\title{
Day-Ahead Congestion Management in Distribution Systems through Household Demand Response and Distribution Congestion Prices
}

Liu, Weijia; Wu, Qiuwei; Wen, Fushuan; Østergaard, Jacob

Published in:

IEEE Transactions on Smart Grid

Link to article, DOI:

10.1109/TSG.2014.2336093

Publication date:

2014

Document Version

Early version, also known as pre-print

Link back to DTU Orbit

Citation (APA):

Liu, W., Wu, Q., Wen, F., \& Østergaard, J. (2014). Day-Ahead Congestion Management in Distribution Systems through Household Demand Response and Distribution Congestion Prices. IEEE Transactions on Smart Grid, 5(6), 2739-2747. https://doi.org/10.1109/TSG.2014.2336093

\section{General rights}

Copyright and moral rights for the publications made accessible in the public portal are retained by the authors and/or other copyright owners and it is a condition of accessing publications that users recognise and abide by the legal requirements associated with these rights.

- Users may download and print one copy of any publication from the public portal for the purpose of private study or research.

- You may not further distribute the material or use it for any profit-making activity or commercial gain

- You may freely distribute the URL identifying the publication in the public portal 


\title{
Day-Ahead Congestion Management in Distri- bution Systems through Household Demand Re- sponse and Distribution Congestion Prices
}

\author{
Weijia Liu, Qiuwei Wu, Member, IEEE, Fushuan Wen, and Jacob Østergaard, Senior Member, IEEE
}

\begin{abstract}
With the development of smart grid technologies, some of the electric demands which are traditionally considered fixed and inflexible will become promising distributed energy resources (DERs) in future power systems. However, the participation of small scale or household energy sources into balancing power might challenge the operation of electric distribution systems and cause congestions. This paper presents a distribution congestion price (DCP) based market mechanism to alleviate possible distribution system congestions. By employing the locational marginal pricing (LMP) model, the proposed DCPs are able to reflect the real congestion cost and further direct the schedule of the responses of electric demands. Based on the NordPool Spot market structure, the interactions between aggregators and the distribution system operator (DSO) are discussed, and the procedure for calculating DCPs is proposed. Finally, a practical Danish $60 \mathrm{kV} / 10.5 \mathrm{kV}$ distribution system is employed as the test case to verify the proposed method for mitigating congestion.
\end{abstract}

Index Terms-Congestion management, household demand response, distribution system, distribution congestion price

\section{NOMENCLATURES}

$\begin{array}{ll}B_{i j} & \begin{array}{l}\text { Imaginary part of the nodal admittance ma- } \\ \text { trix between node } i \text { and } j\end{array} \\ C_{i j} & \text { Charging susceptance between node } i \text { and } j \\ F_{A} & \text { Object function of the aggregators } \\ F_{D} & \text { Object function of the DSO } \\ G & \text { Number of aggregators in the distribution } \\ & \text { system } \\ G_{i j} & \begin{array}{l}\text { Real part of the nodal admittance matrix } \\ \text { between node } i \text { and } j\end{array} \\ H_{A} & \begin{array}{l}\text { Number of domestic houses controlled by } \\ \text { the aggregator }\end{array}\end{array}$

This work is jointly supported by the EcoGridEU project, and National Basic Research Program (973 Program) (No. 2013CB228202).

Weijia Liu and Fushuan Wen are both with the School of Electrical Engineering, Zhejiang University, Hangzhou 310027, China (e-mail: liuweijiamarcel@gmail.com, fushuan.wen@gmail.com).

Qiuwei Wu and Jacob Østergaard are both with the Center for Electric Power and Energy, Department of Electrical Engineering, Technical University of Denmark, 2800 Kgs. Lyngby, Denmark (e-mail: qw@elektro.dtu.dk, joe@elektro.dtu.dk).

\begin{tabular}{|c|c|}
\hline$H(i)$ & f domestic houses at node $i$ \\
\hline$I(k, t)$ & $\begin{array}{l}\text { Comfort parameter of the appliance } k \text { at time } \\
t\end{array}$ \\
\hline$I_{\max }(k)$ & $\begin{array}{l}\text { Maximum comfort parameter value of the } \\
\text { appliance } k\end{array}$ \\
\hline$I_{\min }(k)$ & $\begin{array}{l}\text { Minimum comfort parameter value of the } \\
\text { appliance } k\end{array}$ \\
\hline$K(h)$ & $\begin{array}{l}\text { Number of flexible household appliances at } \\
\text { house } h\end{array}$ \\
\hline$N$ & $\begin{array}{l}\text { Number of load nodes in the distribution } \\
\text { system }\end{array}$ \\
\hline$P_{D}(i, t)$ & Active power demand at node $i$ at time $t$ \\
\hline$P_{D, f i x}(i, t)$ & $\begin{array}{l}\text { Active power of non-flexible demands at } \\
\text { node } i \text { at time } t\end{array}$ \\
\hline$P_{G}(i, t)$ & Active power generation at node $i$ at time $t$ \\
\hline$P_{\text {flex }}(k, t)$ & $\begin{array}{l}\text { Demand planning of the appliance } k \text { at time } t \\
\text { by the aggregators }\end{array}$ \\
\hline$P_{\text {flex.max }}(k, t)$ & $\begin{array}{l}\text { Maximum demand of the appliance } k \text { at time } \\
t\end{array}$ \\
\hline$P_{\text {flex.min }}(k, t)$ & $\begin{array}{l}\text { Minimum demand of the appliance } k \text { at time } \\
t\end{array}$ \\
\hline$P_{i}(h, t)$ & $\begin{array}{l}\text { Demand planning for house } h \text { at time } t \text { for } \\
\text { the next trading day }\end{array}$ \\
\hline$P_{i}^{*}(h, t)$ & $\begin{array}{l}\text { Initial demand planning for house } h \text { at time } t \\
\text { by the aggregators }\end{array}$ \\
\hline$P_{i j, t}$ & $\begin{array}{l}\text { Active power flow between node } i \text { and } j \text { at } \\
\text { time } t\end{array}$ \\
\hline$P_{i, \max }^{*}(h, t)$ & $\begin{array}{l}\text { Maximum flexible demand for house } h \text { at } \\
\text { time } t \text { based on the initial energy bids }\end{array}$ \\
\hline$P_{i, \min }^{*}(h, t)$ & $\begin{array}{l}\text { Minimum flexible demand for house } h \text { at } \\
\text { time } t \text { based on the initial energy bids }\end{array}$ \\
\hline$P_{l o s s}(i j, t)$ & Losses between node $i$ and $j$ at time $t$ \\
\hline$Q_{D}(i, t)$ & Reactive power demand at node $i$ at time $t$ \\
\hline$Q_{G}(i, t)$ & Reactive power generation at node $i$ at time $t$ \\
\hline$Q_{i j, t}$ & $\begin{array}{l}\text { Reactive power flow between node } i \text { and } j \text { at } \\
\text { time } t\end{array}$ \\
\hline
\end{tabular}




\begin{tabular}{|c|c|}
\hline$S_{i j, t}$ & $\begin{array}{l}\text { Apparent power flow between node } i \text { and } j \\
\text { at time } t\end{array}$ \\
\hline$S_{i j \text {,max }}$ & $\begin{array}{l}\text { Maximum acceptable apparent power flow } \\
\text { between node } i \text { and } j\end{array}$ \\
\hline$T$ & Total simulation time horizon \\
\hline$U_{i, t}$ & $\begin{array}{l}\text { Per-unit voltage magnitude at node } i \text { at time } \\
t\end{array}$ \\
\hline$U_{i, \max }$ & $\begin{array}{l}\text { Maximum acceptable voltage magnitude of } \\
\text { node } i\end{array}$ \\
\hline$U_{i, \min }$ & $\begin{array}{l}\text { Minimum acceptable voltage magnitude of } \\
\text { node } i\end{array}$ \\
\hline$g$ & Index of the aggregators, $g=1,2, \ldots, G$ \\
\hline$h$ & Index for the number of houses \\
\hline$i, j$ & $\begin{array}{l}\text { Index of the distribution load nodes, } i \text {, } \\
j=1,2, \ldots, N\end{array}$ \\
\hline$k$ & $\begin{array}{l}\text { Index for the number of flexible household } \\
\text { appliances at house } h\end{array}$ \\
\hline$t$ & Index of the time slots, $t=1,2, \ldots, T$ \\
\hline$\lambda_{D C P}(i, t)$ & $\begin{array}{l}\text { Distribution congestion price at node } i \text { at } \\
\text { time } t\end{array}$ \\
\hline$\lambda_{L M P}(i, t)$ & $\begin{array}{l}\text { Distribution location marginal price at node } \\
i \text { at time } t\end{array}$ \\
\hline$\lambda_{p}(t)$ & $\begin{array}{l}\text { Predicted day-ahead market price at time } t \text { in } \\
\text { the next trading day }\end{array}$ \\
\hline$\theta_{i j, t}$ & $\begin{array}{l}\text { Deviation of phase angle between node } i \text { and } \\
j \text { at time } t\end{array}$ \\
\hline$\Omega_{g}$ & $\begin{array}{l}\text { set of load nodes within the operation of } \\
\text { aggregator } g\end{array}$ \\
\hline
\end{tabular}

\section{INTRODUCTION}

$\mathrm{N}$ OWADAYS, modern power systems are continuously developing towards smart grids with a high level of penetration of renewable energy, electric vehicles (EVs) and distributed energy resources (DERs). Take Denmark as an example, wind energy now amounts to about $28 \%$ of the total Danish electricity consumption, and the Danish government aims to increase the penetration level of wind energy to $50 \%$ by the year of 2020 [1]. With such a high level of wind energy penetration, energy sources at both transmission and distribution levels are required to participate in a new power system operational paradigm with more flexibilities. As far as a distribution system is concerned, a major challenge for the distribution system operator (DSO) is the optimal operation strategies considering the management of DERs and demand responses (DRs). In particular, the DR is believed to be one of the most efficient solutions to accommodate the growing integration of renewable generation and EVs with volatilities and uncertainties through operating the controllable demand for peak shaving and valley filling [2].

Although the DR is not a new idea in power system operation, it receives much attention only in recent years due to the wide application of communication technology, e.g. smart meters and wireless communication [3]. It is believed that employing DR into distribution system operation will help consume the excessive electricity produced by the DERs and reduce the peak demand during high demand periods [4]. Moreover, the adoption of DR in the distribution system operation also enables a higher penetration level of distributed generators (DGs) and EVs. However, improper operation of the controllable demands may result in grid congestion, voltage collapse and other problems in the distribution system [5]. The congestion alleviation in transmission systems has already been extensively studied, while more work is required for examining and mitigating the possible overloading of lines and transformers caused by DERs and unexpected DR in distribution systems [6].

From the perspective of a DSO, the congestion in a distribution system can be handled effectively through proper DR. Generally, the DR can be achieved through direct load control (DLC) or market mechanisms such as distribution congestion prices (DCPs) [7]. Generally, the economic entities in the distribution system such as aggregators and retailers are driven by economic interests. Thus, they will have the potential to respond to market signals so as to minimize their cost. As a result, suitable market mechanisms are required in order to handle congestions in distribution systems through DR and DCPs.

In this paper, a DCP based market mechanism is proposed to influence the behavior of DR for congestion management in distribution systems in the day-ahead electricity market. Since the DCPs should reveal the true cost of congestion, the concept of locational marginal pricing (LMP) is employed to determine the DCPs in the day-ahead market by the DSO [8]. In this paper, controllable household appliances are selected as the DR sources. While influencing the behavior of DR, the customers' comfort requirement must be respected as well.

The rest of the paper is organized as follows: Section II introduces the aggregated control model of the aggregators for household demands. Section III presents the DCP based market mechanism for congestion management and the calculation of DCPs. Section IV presents the simulation results of the proposed concept in congestion alleviation through DR and DCPs. Finally, a conclusion is drawn in Section V.

\section{Aggregated Planning For Household Demands}

Currently, customers are accustomed to consuming electric power without interruptions. As the bi-direction communication between the electricity customers and the associated utilities is coming to reality, certain kinds of household demands can now be seen as flexible and controllable, and have the potential to respond to market signals to minimize their cost without introducing discomfort to the users. Typically, demands controlled by the temperature are regarded as the most important flexible demands in households, as their demands can be altered while maintaining the temperatures within acceptable ranges. These controllable demands include, but not restricted to, heat pumps, refrigeration devices, and water heaters. The air source heat pumps and two kinds of refrigera- 
tion devices are employed as flexible household demands in this work. Detailed thermal models of the flexible household appliances used in this paper are discussed in Appendix A.

However, domestic customers are unlikely to respond to the electricity market themselves. Thus, market entities such as retailers and aggregators will take charge of operating those flexible appliances for the customers and make profits by employing them in the electricity markets. In exchange, the customers will be offered more lucrative contracts as economic compensations..

The operations of these flexible demands are not completely arbitrary as the customers' comfort levels must be respected. As such, the aggregators have to schedule the consumption of these flexible demands according to the price signals to minimize the energy cost, while at the same time maintaining the parameters of the controlled appliances within the acceptable ranges. The objective function of an aggregator in charge of $H_{A}$ domestic houses can be described as:

$$
\text { Minimize } \quad F_{A}=\sum_{t=1}^{T} \sum_{h=1}^{H_{A}} \lambda_{p}(t) P_{i}(h, t)
$$

Meanwhile, the operations of these household demands are limited to their characteristics as well as the customers' requirements. In general, the constraints can be expressed as:

$$
\begin{gathered}
P_{i}(h, t)=\sum_{k=1}^{K(h)} P_{f l e x}(k, t) \\
P_{f l e x \text {,min }}(k, t) \leq P_{f l e x}(k, t) \leq P_{f l e x, \text { max }}(k, t) \\
I_{\text {min }}(k) \leq I(k, t) \leq I_{\text {max }}(k)
\end{gathered}
$$

Equations (2)-(4) denote the total flexible demands of domestic houses, the demand limits of different kinds of appliances at different times, the limits of the comfort parameters of different appliances, respectively. The customers' comfort levels are provided in the power supply contracts, and the comfort parameters can be collected by the aggregators through smart meters.

\section{MARKet Mechanism For Congestion ALLEVIATION}

With flexible appliances available in domestic houses, aggregators and retailers are able to maximize their profits by optimizing the responses of these demands to the fluctuating electricity prices. Compared with autonomous operations, the aggregators will prefer to schedule much more power demand while the price is lower, and vice versa. As a result, the concentrated flexible demand consumption at price valleys is likely to form a new demand peak, and might also cause overloading, voltage drops and other security issues in distribution systems. To alleviate such congestion, certain methods should be taken to prevent the flexible demand peaks and alleviate possible congestions in distribution systems.

\section{A. Congestion Management Strategies}

Distribution system congestion management strategies can be divided into three categories: switch operation (distribution system reconfiguration), DLC [9], and market mechanisms [10]. In general, switch operation is more traditional and has been very well studied. However, it is not very effective while dealing with congestion scenarios in radial network topologies. Moreover, switch operation based methods could not take advantage of the flexibilities of household appliances and other flexible loads such as the EVs. While taking flexible household appliances into account, DLC and market mechanisms are more reasonable in dealing with potential congestions.

The differences between DLC and market methods lie in the responsibilities for controlling the flexible demands. DLC based on the direct control signals to flexible demands to alleviate demand peaks, while market mechanisms depend on market prices or other economic signals in directing the behaviors of flexible demands. Market mechanisms are adopted in this paper as customers are more willing to react to economic signals and make profits rather than being ordered to change their demands.

\section{B. Market Architecture}

In the Nordic region, the day-ahead energy market is operated by NordPool Spot [11]. Market participants must submit their supply and demand bids for the next trading day (NTD) by 12:00 of the present trading day (PTD), and the auction of the supply and demand bids determines the day-ahead energy prices of the NTD. In order to ensure that the congestion alleviation market mechanisms can be successfully integrated into the day-ahead Nordic electricity market, the mechanisms for the alleviation of distribution system congestion must be done before the market clearing of the NordPool Spot, which is 12:00 of the PTD.

As such, the DSO will have to ask the aggregators to submit their initial demand bids for the NTD to the DSO first, i.e., before 11:00 of the PTD. However, the spot price of the NTD is unknown at this point, so historical data will be employed to help estimate the spot price for the NTD. Then DSOs can verify the bids of the aggregators to see whether there will be congestions if their bids become the final bids in NordPool Spot. If there are possible congestions, the DSO will take certain measures and guide the aggregators to alleviate concentrated demand peaks. With market mechanisms, the DSO has to employ reasonable market signals while coordinating with aggregators. The DCP is adopted in this paper for distribution congestion management. Aggregators and retailers will reschedule their energy bids according to the DCPs provided by the DSO. Then the final bids will be submitted to NordPool spot market before 12:00 of the PTD with the DCPs considered. This DCP based congestion alleviation architecture is illustrated in Fig. 1. 


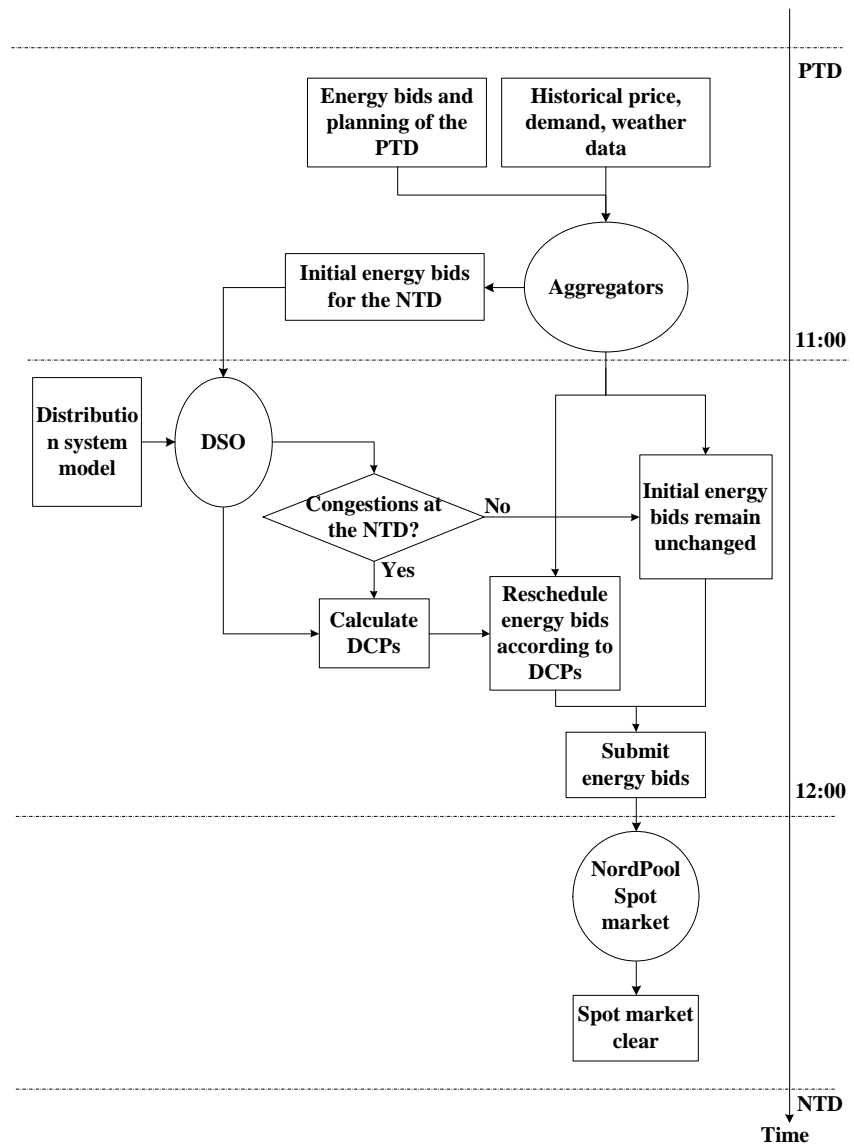

Fig. 1. The DCPs based congestion alleviation market architecture in NordPool spot market.

\section{DCP Calculation}

The concept of DCP is similar to that of the LMP, which is the marginal cost at each node and reflects the extra cost due to congestion and energy losses [12]. Thus, by calculating the LMPs in distribution systems, the elements caused by congestions can be regarded as the DCPs. Generally, LMP is employed in transmission systems and distribution systems with multiple generation units such as DGs [13]. While considering certain household appliances as flexible power demands in the distribution system, LMP can still be calculated as in this case the demands are adjustable.

From the view of the electricity market, the electricity customers should also submit their bids or willingness in scheduling their flexible demands. However, the real cost of regulating these thermal demands in system operation is quite hard to estimate. Moreover, irrational bids may result in low efficiency or failure in the electricity market and system operation. In this paper, the operator in a distribution system will handle the possible congestion in a bid-less market instead of a double auction market [14]. Based on the initial demand bids of the aggregators and detailed information about the availabilities of the flexible demands, the DSO will formulate the distribution LMPs in the day-ahead market for the NTD. If possible congestions have been detected by the DSO, the aggregators will then reschedule their energy bids for the NTD based on both the predicted spot price and the DCPs provided by the DSO. In this way, concentrated demand peaks and the possible congestion in the distribution system will be alleviated.

Alternative current optimal power flow (ACOPF) is employed in this paper to calculate DCPs. The objective of the ACOPF model is to minimize the total electricity supply cost of the whole distribution system in the NTD. The optimization bases on the initial energy bids submitted by the aggregators. With the detail information about the initial schedule and availabilities of all the flexible demands, the DSO can calculate the LMPs for the NTD if there will be congestions. The objective function is shown in (5).

$$
\text { Minimize } \quad F_{D}=\sum_{t=1}^{T} \sum_{i=1}^{N} \lambda_{p}(t) P_{D}(i, t)
$$

The constraints of the distribution system as well as the flexible demands are considered in the ACOPF model, as shown in (6)-(11).

$$
\begin{gathered}
P_{G}(i, t)=P_{D}(i, t)+U_{i, t} \sum U_{j, t}\left(G_{i j} \cos \theta_{i j, t}+B_{i j} \sin \theta_{i j, t}\right) \\
Q_{G}(i, t)=Q_{D}(i, t)+U_{i, t} \sum U_{j, t}\left(G_{i j} \sin \theta_{i j, t}-B_{i j} \cos \theta_{i j, t}\right) \\
U_{i, \min } \leq U_{i, t} \leq U_{i, \max } \\
P_{D}(i, t)=P_{D, f i x}(i, t)+\sum_{h=1}^{H(i)} P_{i}^{*}(h, t) \\
P_{i, \text { min }}^{*}(h, t) \leq P_{i}^{*}(h, t) \leq P_{i, \max }^{*}(h, t) \\
S_{i j, t} \leq S_{i j, \max }
\end{gathered}
$$

Equations (6) and (7) denote the typical AC power flow equations; Eqn. (8) denotes the voltage constraints in the distribution system; Eqn. (9) calculates the total active power demand at each load node; Eqn. (10) bases on the information of initial energy bids provided by the aggregators and limits the availabilities of the flexible demands at different domestic houses; Eqn. (11) is the constraint of the apparent power flow in the distribution system, and $S_{i j, t}$ can be calculated through (12)-(14).

$$
\begin{gathered}
S_{i j, t}=\sqrt{P_{i j, t}^{2}+Q_{i j, t}^{2}} \\
P_{i j, t}=U_{i, t}^{2} G_{i j}-U_{i, t} U_{j, t}\left(G_{i j} \cos \theta_{i j, t}+B_{i j} \sin \theta_{i j, t}\right) \\
Q_{i j, t}=-U_{i, t} U_{j, t}\left(G_{i j} \sin \theta_{i j, t}-B_{i j} \cos \theta_{i j, t}\right)-\frac{1}{2} U_{i, t}^{2} C_{i j}-U_{i, t}^{2} B_{i j}
\end{gathered}
$$

The LMPs can be calculated by solving the above ACOPF model, which can be expressed as,

$$
\lambda_{L M P}(i, t)=\frac{\partial F_{D}}{\partial P_{D}(i, t)}
$$

The LMPs represents the marginal costs at different distribution nodes throughout the time period. However, the marginal costs caused by distribution congestions have to be separated from the LMPs, shown as:

$$
\lambda_{D C P}(i, t)=\lambda_{L M P}(i, t)-\lambda_{p}(i, t)-\sum \frac{\partial P_{\text {loss }}(i j, t)}{\partial P_{D}(i, t)} \lambda_{p}(i, t)
$$

The calculated DCPs illustrate the part of LMPs that are caused by congestions. After solving the ACOPF model, the DSO will be able to publish the DCPs for the aggregators to further modify the demand schedule and alleviate congestions. 


\section{DR Operation Based on DCPs}

The DCPs should be considered in the planning of flexible household demands by the aggregators and retailers for the NTD in the day-ahead market after the verification of DSO is done. The objective functions for aggregators still aim to minimize the total energy cost at the NTD, and the DCPs should also be taken into account. In practice, it is possible that multiple aggregators exist in the distribution system, and each aggregator will optimize the planning of flexible demands within its own control area. The objective function for aggregator $g$ is described in (17), while all the constraints shown in (2)-(4) remain the same.

$$
\text { Minimize } \quad F_{A}=\sum_{t=1}^{T} \sum_{i \in \Omega_{g}} \sum_{h=1}^{H(i)}\left(\lambda_{p}(t)+\lambda_{D C P}(i, t)\right) P_{i}(h, t)
$$

Through the optimization with DCPs considered, these aggregators will determine their control strategies of flexible demands in the NTD by shifting the loads based on the predicted energy price and the DCP profiles.

\section{CASE STUdies}

In order to verify the effectiveness of the proposed congestion alleviation mechanism using DCPs in distribution systems, a Danish $60 \mathrm{kV} / 10.5 \mathrm{kV}$ distribution system has been employed in case studies [15]. The topology of the test system is shown in Fig. 2. The test system contains 30 distribution load nodes. The discretized demand response model for the aggregators and the ACOPF model for the DSO in DCPs calculation are solved by GAMS/CPLEX and GAMS/CONOPT, which are high-performance commercial solvers for the linear programming and non-linear programming models, respectively $[16,17]$.

\section{A. Simulation Descriptions}

1) Domestic houses: Assume that there are 60 domestic houses at each distribution load node, and the floor area of all the houses randomly varies from $40 \mathrm{~m}^{2}$ to $250 \mathrm{~m}^{2}$. In practice, the thermal characteristics of all the houses of customers will vary from each other in terms of structure, material, etc. In this case study, the thermal characteristics of domestic houses are simplified to have the similar structure and properties, thus the thermal models of different houses can be described based on their floor areas. Also, the case studies are based on the normal climate data of the winter in Denmark, so all the houses will have to use their heat pumps or other heating devices. For more accurate modeling of the domestic houses, aggregators could use the collected data and analyze the simplification errors, and further modify the characteristics of the models accordingly. Detailed comfort settings and the parameters of different household appliances are described in Appendix B.

2) Aggregators: Two aggregators are assumed to participate in the distribution system operation in this case study, as shown in Fig. 2. According to Fig. 1, the aggregators have to estimate the initial conditions of flexible appliances at the beginning of the NTD. The initial conditions of the NTD can be estimated by the real-time comfort parameters during bidding hours through smart meters and the demand schedules at the PTD. Also, all the appliances are assumed to operate following the aggregators' schedules.

3) Simulation scenarios: Two simulation scenarios listed in Table I have been used to test the validity of the proposed method. In both scenarios, the congestion happens at the $60 \mathrm{kV} / 10.5 \mathrm{kV}$ substation NOR-NOR1. Both the night peak and morning peak spot price profiles were obtained from the spot prices of the DK-west region in the NordPool spot market. Moreover, the estimated spot price for the NTD by the aggregators and the DSO is assumed to be perfect. If an estimation error exists, the congestions in the distribution system can still be further handled in the real-time market and other control strategies, which is out of the scope of this paper.

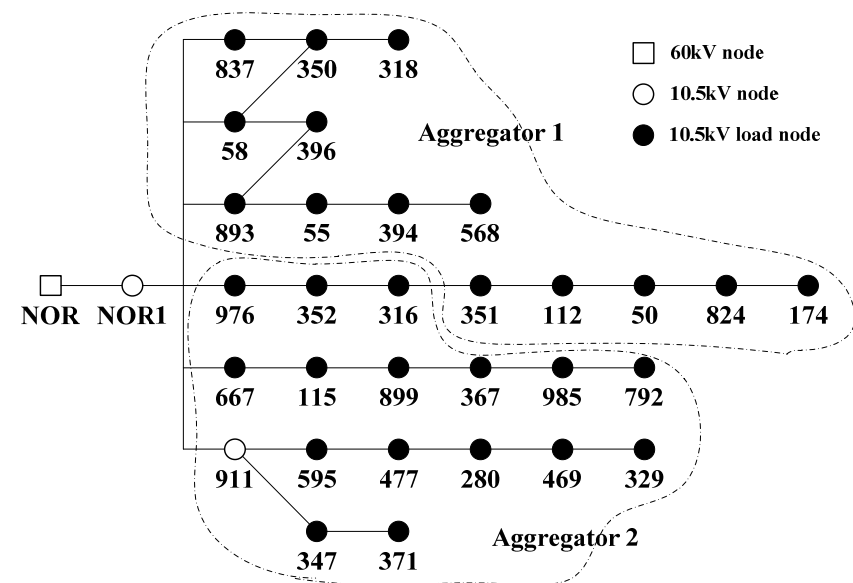

Fig. 2. Topology of the Danish $60 \mathrm{kV} / 10.5 \mathrm{kV}$ distribution system.

TABLE I

CAST STUDY SCENARIOS

\begin{tabular}{ccc}
\hline $\begin{array}{c}\text { Scenario } \\
\text { No. }\end{array}$ & Price profile & Congestion scenario \\
\hline 1 & Night peak & $\begin{array}{c}\text { Overloading through trans- } \\
\text { former NOR-NOR1 } \\
\text { Overloading through trans- } \\
\text { former NOR-NOR1 }\end{array}$ \\
\hline
\end{tabular}

\section{B. Simulation Results}

The difference between these two scenarios is the time period of higher (or lower) spot prices. As the customers will use more electricity during the evening, the non-flexible part of power demand, such as lighting and cooking, will be significantly higher than that during the daytime.

The DCPs calculated by the DSO in both scenarios are shown in Fig. 3 and 4, respectively. The initial energy planning and the final demand bids with the consideration of DCPs by the aggregators in both scenarios are demonstrated in Fig. 5 and 6, respectively. 


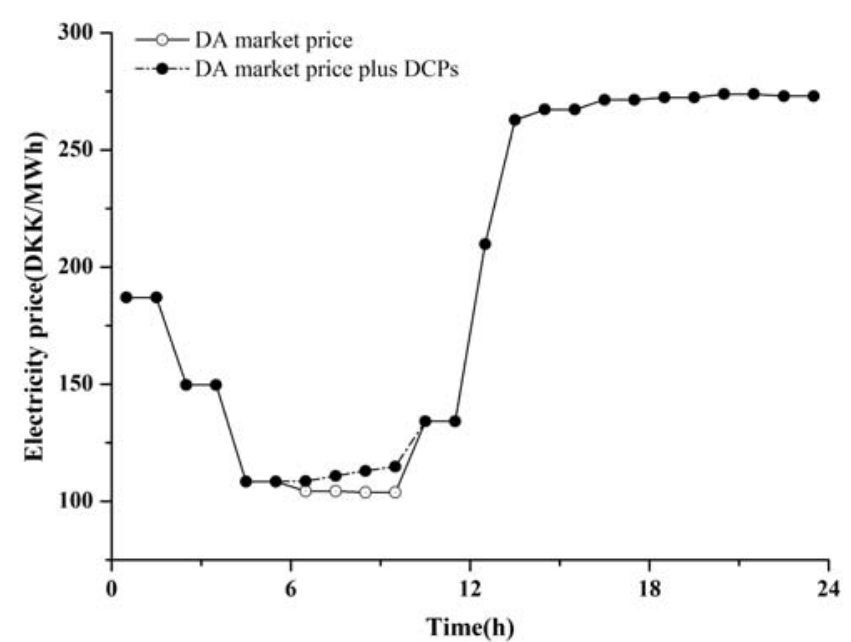

Fig. 3. Profiles of spot market price and the calculated DCPs of scenario 1.

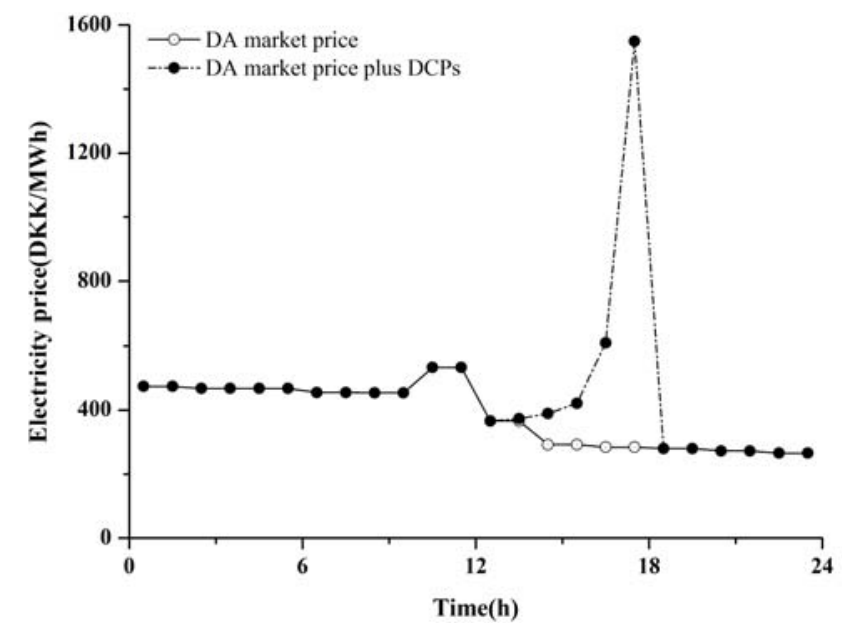

Fig. 4. Profiles of spot market price and the calculated DCPs of scenario 2.

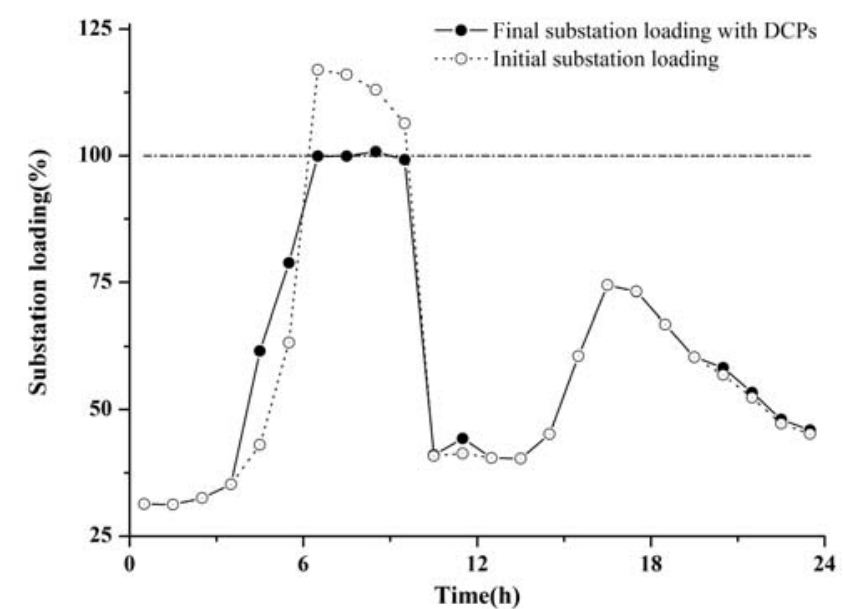

Fig. 5 Profiles of apparent power flows through substation NOR-NOR1 in scenario 1.

\section{Results Analysis}

Figures 5 and 6 demonstrate that the proposed DCP strategy can alleviate the concentrated demand peaks and the congestions in the distribution system. With the information of DCPs, aggregators rearrange the demands of flexible appli- ances. Take the flexible demands at node 316 and 824 in scenario 1 as examples. The flexible demand schedule at these two load nodes are the same when aggregators submit their initial plans to the DSO, but the final demand bids are quite different, as shown in Fig. 7.

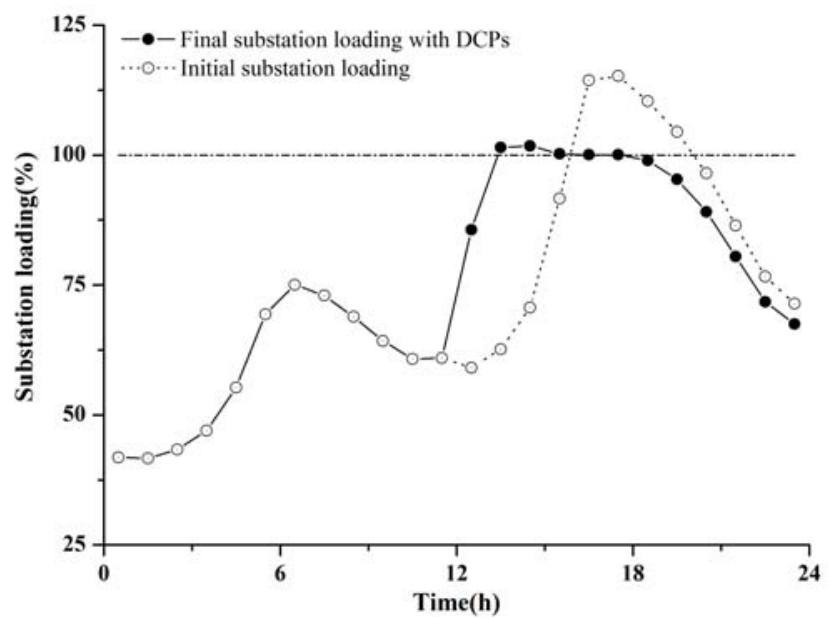

Fig. 6 Profiles of apparent power flows through substation NOR-NOR1 in scenario 2 .

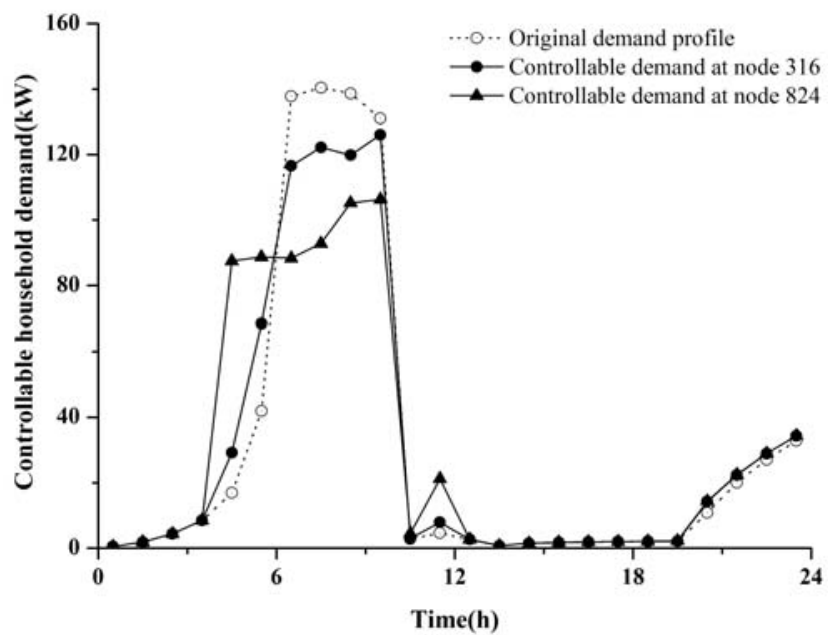

Fig. 7 Profiles of initial and rescheduled flexible demands at node 316 and 824 of scenario 1 .

Table II lists the maximum loading in both scenarios. It can be noted that slight congestion still exists, and the congestions with morning peak price profiles are harder to alleviate. Generally, the proposed DCPs mechanism can be considered feasible in distribution congestion alleviation since the maximum overloading with DCPs only exceeds less than $1.0 \%$ in night peak price profiles and $2.0 \%$ in morning peak price profiles.

The possible reasons for the overloading can be due to the nature of the demand response characteristics of household loads and the flexibilities in planning the loads among all the 60 houses at each load node. Even with DCPs, the aggregators can still adjust the demands within those 60 domestic houses at each node. Besides, the time resolution of the DA market is one hour, so the results of the discretized DR models will be quite rough. 
TABLE II

SUBSTATION LOADING WITH AND WITHOUT DCPS

\begin{tabular}{ccc}
\hline $\begin{array}{c}\text { Scenario } \\
\text { No. }\end{array}$ & $\begin{array}{c}\text { Initial maximum line } \\
\text { loading }\end{array}$ & $\begin{array}{c}\text { Maximum line loading } \\
\text { with DCPs }\end{array}$ \\
\hline 1 & $116.94 \%$ & $100.78 \%$ \\
2 & $115.20 \%$ & $101.81 \%$ \\
\hline
\end{tabular}

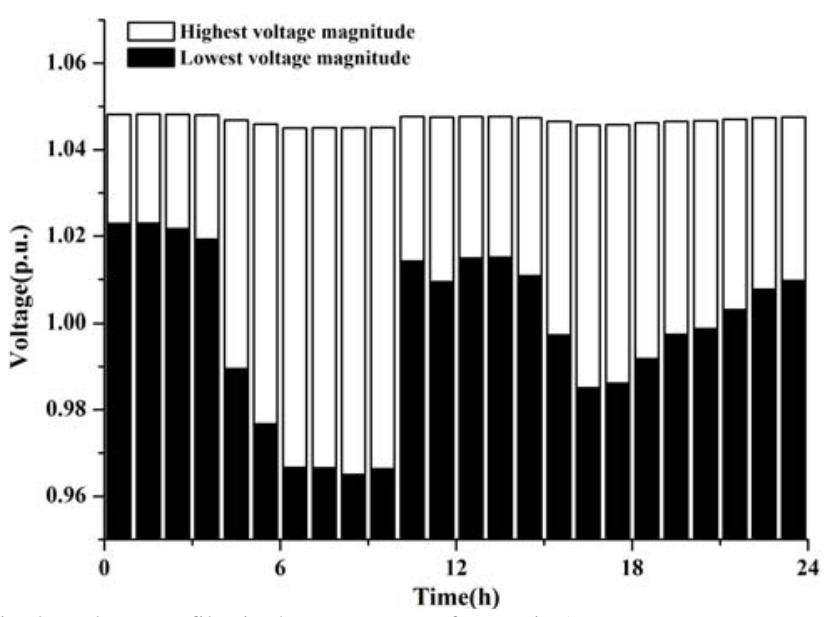

Fig. 8 Voltage profiles in the test system of scenario 1.

Fig. 8 demonstrates the highest and lowest voltages among all the distribution load nodes for the NTD of scenario 1 . Although the demand bids submitted by the aggregators are not exactly the same with the results of ACOPF optimization by the DSO, the nodal voltages can still be kept within acceptable ranges. However, if the distribution transformer's tap changes inappropriately, the flexibilities of household appliances could result in unexpected voltage drops or voltage collapses. In this case, the DSO is not able to formulate suitable DCPs, and other methods such as modifying the transformer's tap and DLC should be adopted to prevent voltage failures in the distribution system.

\section{Discussions}

As discussed in Section III, the congestions in distribution systems can be solved with several different methods. Based on the structure of NordPool Spot electricity market, the DCPs based model is adopted in this paper.

On the other hand, another market mechanism bases on the declared cost of scheduling flexible demands is also an applicable alternative. However, the major drawback of this method is the difficulties in calculating the real cost of changing the demands of the flexible appliances. As shown in [18], the final settled spot price in the distribution system is much higher than the original price. Moreover, the reasonable treatment of the large amount of excessive purchasing cost introduced by this approach is still unclear. As a result, the electricity market is not likely to perform in a very efficient way.

Besides, this paper assumes that all the flexible appliances will operate following the aggregators' schedules. In reality, the demands may be altered from the aggregators' schedules due to unforeseeable factors such as device failures and the customers' autonomous operations. Such mismatches can be compensated through intra-day market, real-time market or DLC methods. In additions, the aggregators may compensate possible economic losses caused by those mismatches through modifying the power supply contracts with the customers who failed to respond to the schedule.

\section{CONCLUSIONS}

This paper presents a market mechanism of DCPs for the congestion alleviation in distribution systems through the response of household demands. The aggregators and retailers are able to schedule the electricity consumption of flexible demands to maximize their profits. At the same time, it becomes possible for the DSO to set up DCPs as a market mechanism to alleviate possible congestion in distribution systems in the day-ahead electricity market. The DCPs based congestion alleviation strategy has been validated by the case studies using a practical Danish $10.5 \mathrm{kV}$ distribution system. Though slight congestions still exist with DCPs implemented, the overloading rates are very low and acceptable since the distribution lines and transformers have overloading capacities.

Still, there is a lot of work to be done in the near future concerning several major issues in distribution systems. For instance, the accurate estimation of the spot market price; the coordination between day-ahead market and real-time market; multi-objective distribution system optimization considering congestions, voltage distribution and network losses; the congestion alleviation strategies with the integration of DR, EVs and DGs, etc. Besides, the integration and coordination of different congestion management approaches are also promising trends in handling distribution system congestions.

\section{APPENDIX A}

\section{THERMAL MODELS OF HOUSEHOLD APPLIANCES}

1) Thermal model for houses: For simplification, the thermal models of individual houses are comprised of three parts, which are the interior of the house, the surface of the house including walls and windows, and the exterior [19]. Let $A, H$, $S, W, E$ and $V$ denote the floor area, height, surface area, window area, exterior wall area, air ventilation rate of the house, respectively. In this paper, $H$ is assumed to be $2.5 \mathrm{~m}, V$ is assumed to be $50 \%$ per hour, and the windows comprise $20 \%$ of the exterior wall area of all the houses. Also, it is assumed that at any time during the day, only $50 \%$ of the exterior wall are exposed to sunlight. For a given value of $A$, the value of $S, E$ and $W$ can be calculated as follows [20],

$$
\begin{gathered}
S=2 A+4 H \sqrt{A} \\
E=H \sqrt{A} \\
W=0.2 E
\end{gathered}
$$

Furthermore, let $C_{i}, C_{s}, R_{i s}, R_{i e}$ and $R_{s e}$ denote the heat capacity of house interior, heat capacity of the house surface, heat transfer coefficient (HTC) between the interior and surface, HTC between the interior and exterior, and HTC between the surface and exterior, respectively. These parameters can be obtained as follows [20], 


$$
\begin{gathered}
C_{i}=1.3 \times 10^{4} A(\mathrm{~J} / \mathrm{K}) \\
C_{s}=3.6 \times 10^{2} A(\mathrm{~J} / \mathrm{K}) \\
R_{i s}=7.69 S(\mathrm{~W} / \mathrm{K}) \\
R_{i e}=0.34 V A H(\mathrm{~W} / \mathrm{K}) \\
R_{s e}=\frac{7.69 S(69.05+1.07 A)}{7.69 S-(69.05+1.07 A)}(\mathrm{W} / \mathrm{K})
\end{gathered}
$$

2) Thermal model for heat pumps: The dynamics of air source heat pumps mainly relate to the interior air temperature, the ambient air temperature, the house surface temperature, and the HTC between them. The thermal dynamics of air source heated house can be described by (26) and (27) [21],

$$
\begin{array}{r}
\frac{d T_{i}}{d t}=\frac{1}{C_{i}}\left(Q_{H A}+\xi_{s} W Q_{s}+R_{i s}\left(T_{s}-T_{i}\right)+R_{i e}\left(T_{e}-T_{i}\right)\right) \\
\frac{d T_{s}}{d t}=\frac{1}{C_{s}}\left(\xi_{s} E Q_{s}+R_{i s}\left(T_{i}-T_{s}\right)+R_{s e}\left(T_{e}-T_{s}\right)\right)
\end{array}
$$

where $T_{i}, T_{s}, T_{e}, Q_{H A}, Q_{s}$ and $\xi_{s}$ represent the interior temperature, the surface temperature, the ambient temperature, the heat output of the air source heat pump, the solar radiation and the efficiency of solar radiation, respectively.

3) Thermal model for refrigeration devices: Two types of refrigeration devices are considered in this paper, one is the combined refrigerator and freezer [22], and the other is the large household refrigerator [23]. Both refrigeration thermal models are obtained from the simplified models described in [24]. The defrosting cycle of refrigeration devices is not considered in this paper, for it is controlled by the defrost timer other than the user or the aggregator.

a) Combined refrigerator and freezer: The combined refrigerator and freezer can be represented by four thermal masses, namely refrigeration contents, freezing contents, the refrigeration interior, and the freezing structure. The temperatures of these four masses are denoted as $T_{c 1}, T_{c 2}, T_{c 3}$ and $T_{c 4}$, respectively. The thermal dynamic models can be described as,

$$
\begin{gathered}
\frac{d T_{c 1}}{d t}=\frac{1}{C_{c 1}}\left(R_{c 13}\left(T_{c 3}-T_{c 1}\right)\right) \\
\frac{d T_{c 2}}{d t}=\frac{1}{C_{c 2}}\left(R_{c 24}\left(T_{c 4}-T_{c 2}\right)\right) \\
\frac{d T_{c 3}}{d t}=\frac{1}{C_{c 3}}\left(R_{c 13}\left(T_{c 1}-T_{c 3}\right)+R_{c 34}\left(T_{c 4}-T_{c 3}\right)+R_{i c}\left(T_{i}-T_{c 3}\right)\right) \\
\frac{d T_{c 4}}{d t}=\frac{1}{C_{c 4}}\left(R_{c 34}\left(T_{c 3}-T_{c 4}\right)+R_{c 24}\left(T_{c 2}-T_{c 4}\right)-Q_{F C}\right)
\end{gathered}
$$

where $C_{c 1}, C_{c 2}, C_{c 3}$ and $C_{c 4}$ represent the heat capacity of the refrigeration contents, the freezing contents, the refrigeration interior, and the freezing structure, respectively. $R_{c 13}, R_{c 24}, R_{c 34}$ and $R_{i c}$ denote the HTC between the refrigeration contents and the refrigeration interior, the freezing contents and the freezing structure, the refrigeration interior and the freezing structure, the refrigeration interior and the air inside the house, respectively. $Q_{F C}$ denotes the heat consumption of the combined refrigerator and freezer.

b) Large household refrigerator: Let $T_{l 1}, T_{l 2}$ and $T_{l 3}$ rep- resent the temperatures of the refrigeration contents, the refrigeration interior and the cooling circuit, respectively. The thermal dynamic model of the large household refrigerators can be described as follows,

$$
\begin{gathered}
\frac{d T_{l 1}}{d t}=\frac{1}{C_{l 1}}\left(R_{l 12}\left(T_{l 2}-T_{l 1}\right)\right) \\
\frac{d T_{l 2}}{d t}=\frac{1}{C_{l 2}}\left(R_{l 12}\left(T_{l 1}-T_{l 2}\right)+R_{l 23}\left(T_{l 3}-T_{l 2}\right)+R_{l l}\left(T_{i}-T_{l 2}\right)\right) \\
\frac{d T_{l 3}}{d t}=\frac{1}{C_{l 3}}\left(R_{l 23}\left(T_{l 2}-T_{l 3}\right)-Q_{F L}\right)
\end{gathered}
$$

where $C_{l 1}, C_{l 2}$ and $C_{l 3}$ represent the heat capacity of the refrigeration contents, the refrigeration interior and the cooling circuit, respectively. $R_{l 12}, R_{l 23}$ and $R_{i l}$ denote the HTC between the refrigeration contents and the refrigeration interior, the refrigeration interior and the cooling circuit, the refrigeration interior and the air inside the house, respectively. $Q_{F L}$ denotes the heat consumption of the refrigerator.

4) Thermal constraints: In addition to the thermal models above, certain constraints must be respected to satisfy the needs of customers, as shown in (35)-(40),

$$
\begin{gathered}
0 \leq Q_{H A}(h, t) \leq Q_{H A, \text { max }}(h, t) \\
0 \leq Q_{F C}(h, t) \leq Q_{F C, \text { max }}(h, t) \\
0 \leq Q_{F L}(h, t) \leq Q_{F L, \text { max }}(h, t) \\
T_{i, \text { min }}(h) \leq T_{i}(h, t) \leq T_{i, \text { max }}(h) \\
T_{c 3, \text { min }}(h) \leq T_{c 3}(h, t) \leq T_{c 3, \text { max }}(h) \\
T_{l 2, \text { min }}(h) \leq T_{l 2}(h, t) \leq T_{l 2, \text { max }}(h)
\end{gathered}
$$

where $T_{i, \text { min }}(h), T_{i, \text { max }}(h), T_{c 3 \text {,min }}(h), T_{c 3 \text {,max }}(h), T_{l 2, \text { min }}(h)$ and $T_{l 2 \text {,max }}(h)$ denote the minimum and maximum acceptable temperature of $T_{i}, T_{c 3}$ and $T_{l 2}$ according to the customer's requirement at house $h$, respectively; $Q_{H A \text {, max }}(h, t), Q_{F C \text {, max }}(h, t)$ and $Q_{F L \text {,max }}(h, t)$ represent the maximum heat consumption of the air source heat pump, the combined refrigerator and freezer, and the large household refrigerator of house $h$ at time $t$, respectively.

\section{APPENDIX B}

\section{CASE STUdy PARAMETERS}

TABLE III

Air SOURCE HEAT PUMP PARAMETERS

\begin{tabular}{cccc}
\hline Heat pump size & Small & Medium & Large \\
\hline$\overline{Q_{H}}(\mathrm{~W})$ & 6388 & 8700 & 15150 \\
$Q_{H, \text { slope }}(\mathrm{W} / \mathrm{K})$ & 62.5 & 78 & 95 \\
COP & 3.138 & 3.315 & 3.520 \\
\hline
\end{tabular}

TABLE IV

\begin{tabular}{cc||cc} 
PARAMETERS OF COMBINED REFRIGERATOR AND FREEZERS \\
\hline$C_{c 1}(\mathrm{~kJ} / \mathrm{K})$ & 4.0 & $C_{c 24}(\mathrm{~W} / \mathrm{K})$ & 1.875 \\
$C_{c 2}(\mathrm{~kJ} / \mathrm{K})$ & 6.0 & $C_{c 34}(\mathrm{~W} / \mathrm{K})$ & 1.35 \\
$C_{c 3}(\mathrm{~kJ} / \mathrm{K})$ & 0.5 & $C_{i c}(\mathrm{~W} / \mathrm{K})$ & 1.2 \\
$C_{c 4}(\mathrm{~kJ} / \mathrm{K})$ & 1.35 & $Q_{F C \text {, max }}(\mathrm{W})$ & 300 \\
$C_{c 13}(\mathrm{~W} / \mathrm{K})$ & 4.375 & $\mathrm{COP}$ & 1.306 \\
\hline
\end{tabular}

TABLE V

PARAMETERS OF LARGE HOUSEHOLD REFRIGERATORS 


\begin{tabular}{cc||cc}
\hline$C_{l 1}(\mathrm{~kJ} / \mathrm{K})$ & 251 & $C_{l 23}(\mathrm{~W} / \mathrm{K})$ & 5 \\
$C_{l 2}(\mathrm{~kJ} / \mathrm{K})$ & 13 & $C_{i l}(\mathrm{~W} / \mathrm{K})$ & 12 \\
$C_{l 3}(\mathrm{~kJ} / \mathrm{K})$ & 1.0 & $Q_{F L, \text { max }}(\mathrm{W})$ & 421 \\
$C_{l 12}(\mathrm{~kJ} / \mathrm{K})$ & 30 & $C O P$ & 1.306 \\
\hline
\end{tabular}

TABLE VI

PARAMETERS OF DOMESTIC HOUSES

\begin{tabular}{cc||cc}
\hline$\xi_{s}$ & $50 \%$ & $T_{c 3, \max }\left({ }^{\circ} \mathrm{C}\right)$ & 4 \\
$T_{i, \min }\left({ }^{\circ} \mathrm{C}\right)$ & 20 & $T_{l 2, \min }\left({ }^{\circ} \mathrm{C}\right)$ & 1 \\
$T_{i, \max }\left({ }^{\circ} \mathrm{C}\right)$ & 24 & $T_{l 2, \max }\left({ }^{\circ} \mathrm{C}\right)$ & 4 \\
$T_{c 3, \min }\left({ }^{\circ} \mathrm{C}\right)$ & 1 & & \\
\hline
\end{tabular}

\section{REFERENCES}

[1] Danish Ministry of Climate, Energy and Building, "Smart Grid Strategy - The future of intelligent energy,” Apr. 2013, [Online]. Available: http://www.kebmin.dk/

[2] K. Dietrich, J. M. Latorre, L. Olmos, and A. Ramos, "Demand response and its sensitivity to participation rates and elasticities," International Conference on the European Energy Market (EEM), Zagreb, Croatia, pp. 717-716, May 2011.

[3] L. Zheng, N. Lu, and L. Cai, "Reliable wireless communication networks for demand response control,” IEEE Trans. Smart Grid, vol. 4, no. 1, pp. 133-140, Mar. 2013.

[4] J. Liu, M. M. A. Salama, and R. R. Mansour, "Identify the impact of distributed resources on congestion management," IEEE Trans. Power Del., vol. 20, no. 3, pp. 1998-2005, Jul. 2005.

[5] J. Medina, N. Muller, and I. Roytelman, "Demand response and distribution grid operations: opportunities and challenges,” IEEE Trans. Smart Grid, vol. 1, no. 2, pp. 193-198, Sep. 2010.

[6] H. Saele and O. S. Grande, "Demand response from household customers: experiences from a pilot study in Norway," IEEE Trans. Smart Grid, vol. 2, no. 1, pp. 102-109, Mar. 2011.

[7] P. Palensky and D. Dietrich, "Demand side management: demand response, intelligent energy systems, and smart loads," IEEE Trans. Ind. Inform., vol. 7, no. 3, pp. 381-388, Aug. 2011.

[8] N. O’Connell, Q. W. Wu, J. Østergaard, A. H. Nielsen, S. T. Cha, and Y Ding, "Day-ahead tariffs for the alleviation of distribution grid congestion from electric vehicles,” Electr. Pow. Syst. Res., vol. 92, pp. 106-114, Nov. 2012.

[9] C. M. Chu and T. L. Jong, “A novel direct air-conditioning load control method,” IEEE Trans. Power Syst., vol. 23, no. 3, pp. 1356-1363, Aug. 2008.

[10] D. T. Nguyen, M. Negnevitsky, and M. de Groot, "Market-based demand response scheduling in a deregulated environment," IEEE Trans. Smart Grid, vol. 4, no. 4, pp. 1948-1956, Dec. 2013.

[11] NordPool Spot, "Baltics market setup," [Online]. Available: http://www.nordpoolspot.com

[12] E. Litvinov, "Design and operation of the locational marginal pricesbased electricity markets," IET Gener. Transm. Distrib., vol. 4, no. 2, pp. 315-323, Feb. 2010.

[13] K. Shaloudegi, N. Madinehi, S. H. Hosseinian, and H. A. Abyaneh, “A novel policy for locational marginal price calculation in distribution systems based on loss reduction allocation using game theory," IEEE Trans. Power Syst., vol. 27, no. 2, pp. 811-820, May 2012

[14] J. C. Fuller, K. P. Schneider, and D. Chassin, "Analysis of residential demand response and double auction markets," IEEE Power and Energy Society General Meeting, San Diego, CA, USA, pp. 1-7, Jul. 2011.

[15] J. Kumagai, “The smartest, greenest grid,” IEEE Spectrum, [Online]. Available: http://spectrum.ieee.org/energy/the-smarter-grid/the-smartestgreenest-grid

[16] Cplex Solver Manual, [Online]. Available: http://www.gams.com/dd/ docs/solvers/cplex.pdf

[17] CONOPT Solver Manual, [Online]. Available: http://www. gams.com/ dd/docs/solvers/conopt.pdf

[18] J. Hu, S. You, M. Lind, and J. Østergaard, "Coordinated charging of electric vehicles for congestion prevention in the distribution grid," IEEE Trans. Smart Grid, vol, 5, no. 2, pp. 703-711, Mar. 2014.

[19] S. Karmacharya, G. Putrus, C. Underwood, and K. Mahkamov, "Thermal modeling of the building and its HVAC system using Matlab/Simulink,” $2^{\text {nd }}$ International Symposium on Environment Friend- ly Energies and Applications (EFEA), Newcastle upon Tyne, UK, pp. 202-206, Jun. 2012.

[20] Dansk Standard, "DS 418 - Beregning af bygningers varmetab, $6^{\text {th }}$ ed." Denmark, 2002.

[21] R. C. Sonderegger, "Dynamic models of house heating based on equivalent thermal parameters,” Ph.D. thesis, Report PU/CEES 57 Center for Energy and Environmental Studies, Princeton University, Princeton, NJ, 1977.

[22] J. A. Short, D. G. Infield, and L. L. Freris, "Stabilization of grid frequency through dynamic demand control,” IEEE Trans. Power Syst., vol. 22, no. 3, pp. 1284-1293, Aug. 2007.

[23] P. Nyeng, J. Østergaard, M. Togeby, and J. Hethey, "Design and implement of frequency-responsive thermostat control," $45^{\text {th }}$ International Universities Power Engineering Conference (UPEC), Cardiff, Wales, pp. 1-6, Aug.-Sep. 2010.

[24] E. L. Zaparoli and M. J. S. de Lemos, "Simulation of transient response of domestic refrigeration systems," Proc. of the Int. Refrigeration Conf. Purdue Univ., W. Lafayette, IN, USA, pp. 495-500, 1996.

Weijia Liu received the B.E. degree in electrical engineering from Zhejiang University, Hangzhou, China, in 2011.

He is pursuing his Ph.D. degree in the School of Electrical Engineering, Zhejiang University, Hangzhou, China. He had worked as a project assistant at the Department of Electrical Engineering, The Hong Kong Polytechnic University, Hong Kong, from 2012 to 2013. He had worked as a research assistant at the Center for Electric Power and Energy, Department of Electrical Engineering, Technical University of Denmark, Denmark, from 2013 to 2014. His main research interests are power system restoration and smart grids.

Qiuwei Wu obtained his B. Eng. and M. Eng. from Nanjing University of Science and Technology, Nanjing, P. R. China, in 2000 and 2003, respectively, both in Power System and Automation. He obtained his PhD degree from Nanyang Technological University, Singapore in 2009 in Power System Engineering.

He worked as a senior R\&D engineer in Vestas Technology R\&D Singapore Pte. Ltd. from Mar. 2008 to Oct. 2009. He was a PostDoc with Centre for Electric Technology (CET), Technical University of Denmark (DTU) from Nov. 2009 to Oct. 2010, and an Assistant Professor from Nov. 2010 - Aug. 2013. He has been an Associate Professor with the same center since Sept. 2013.

His research interests are integration of electrical vehicles to power grid for high penetration of wind power, integration study for wind farms and reliability improvement, and price volatility reduction in restructured power systems using demand response programs.

Fushuan Wen received his B.E. and M.E. degrees from Tianjin University, China, in 1985 and 1988, respectively, and Ph.D. from Zhejiang University, China, in 1991, all in electrical engineering.

He joined the faculty of Zhejiang University in 1991, and has been a full professor and the director of the Institute of Power Economics and Information since 1997, and the director of Zhejiang University-Insigma Joint Research Center for Smart Grids since 2010. He had been a university distinguished professor, the deputy dean of the School of Electrical Engineering and the director of the Institute of Power Economics and Electricity Markets in South China University of Technology (SCUT), China, from 2005 to 2009. His current research interests lie in power industry restructuring, power system alarm processing, fault diagnosis and restoration strategies, as well as smart grids and electric vehicles.

Prof. Wen is an associate editor of JOURNAL OF ENERGY ENGINEERING, hosted by American Society of Civil Engineers (ASCE).

Jacob Østergaard obtained his MSc in Electrical Engineering from Technical University of Denmark (DTU) in 1995.

He was with Research Institute of Danish Electric Utilities for 10 years where he did research within power system transmission and distribution and was responsible for developing industrial-academic collaboration. Since 2005 he has been Professor and Head of Centre for Electric Technology (CET), DTU. His research interests cover Smart Grids with focus on system integration of renewable energy and distributed energy resources, control architecture for future power system, and flexible demand. 
Prof. Østergaard is serving in several professional organizations, boards and steering committees. He is head of the Danish experimental platform for electric power and energy, PowerLabDK, and has been member of the EU Smart Grids advisory council. In 2009 he received the IBM Faculty Award. 